S sciendo International Conference KNOWLEDGE-BASED ORGANIZATION
Vol. XXVII

\title{
THE THREAT THAT IS REPRESENTED BY THE UNAUTHORIZED FLIGHT OF THE RPAS AND THE ANTI-DRONE SYSTEMS
}

\author{
Laurențiu-Răducu POPESCU \\ "Carol I" National Defense University, Bucharest, Romania \\ lpopescu2011@gmail.com
}

\begin{abstract}
The unauthorized flights of the RPAS (Remotely Piloted Aircraft System) represent serious threats to the security of the aircraft with human crew on board, to the security of the troops in the theatre of operations as well as to the critical infrastructures and why not to the security of the civilian population. The purpose of the study was to identify which events have occurred recently related to RPAS and which of these represent real challenges to security and defense. Specific regulations and standards are not enough to control the RPAS phenomenon. I used specialized documents and studies, information and conclusions presented by the media, comparative analysis as research methods. Also, I highlighted the risks represented by RPAS. I have presented in chronological order some of the events that have taken place lately related to the use of RPAS, to demonstrate their wide spectrum of use. Even if several C-RPAS systems are installed (for anti-drone protection), an important area cannot be secured if you do not have enough systems capable of covering the entire restricted airspace. The development of anti-drone systems (C-RPAS) is rapidly required.
\end{abstract}

\section{Keywords: RPAS, C-UAS, UAS, UAV, C-RPAS}

\section{Introduction}

Due to the exponential development of aircraft systems without human pilot on board (RPAS - Remotely Piloted Aircraft System - the new name of the UAVs in the ICAO documentation, drones, UAV Unmanned Aerial Vehicle, UAS Unmanned Aerial System or how they will be called in the future) and especially their use in airspace, the concern of military and civil liability factors has also begun to increase regarding the safety of conducting flights with pilot / human crew on board. Although RPAS have a development and evolution over time, comparable to those aircraft with human pilot on board (since the 20th century), the regulations and standards specific to the field have not kept up. More and more entities with national and international regulatory role began to grind about this global phenomenon, the RPAS phenomenon.

\section{The RPAS phenomenon}

However, specific regulations and standards are not enough to control the RPAS phenomenon. Why should this RPAS phenomenon be controlled? Because a multitude of negative events that have happened lately related to the RPAS, lead us to this conclusion. I will discuss this further, but before that I would like to emphasize the importance of setting up structures, mechanisms, processes that monitor, watch and implement these specific regulations and standards. Of course, if structures are to appear automatically, the competent personnel trained for this sector of the economy will also appear, which is an extremely large 
and complex sector. Therefore, for the proper functioning of these structures, it will also be necessary to provide specific means / tools for monitoring, controlling and combating the RPAS. In other words, over the last five years and even earlier, a new sector of activity, namely the sector of anti-drone systems, has emerged. Next for a better presentation, I will shorten the antidrone system with C-RPAS (Counter Remotely Piloted Aircraft System).

\subsection{The importance of C-RPAS}

Other abbreviations such as C-UAS or CUAV also appear in the specialized literature. I stated that the C-RPAS systems have recently appeared because I relied on a study done by the researchers from the Sandia National Laboratories, which mentioned that on the market there were only 10 such systems in the period 20082015. We are noticing at the moment, an evolution of this sector, of combating drones, which exceeds all expectations. Thus, in the December 2019 study, entitled "COUNTER-DRONE SYSTEMS" [1] signed by Arthur Holland Michel, in the second edition, there are a number of 537 products from manufacturers around the world. This study was conducted under the patronage of the Center for the Study of the Drone at Bard College. The database of this study is all the more credible, given the fact that it was assisted by the Vice President for Research and Consultancy of the Region of America, Frost \& Sullivan, Mr. Michael Blades [2]. The study involved a special commitment from researchers, both scientifically and financially, being part of the program "Counter-Drone Systems: Implications for Norway in an EU and NATO context" of the Peace Research Institute Oslo. The military interest is evident through the funding of this study by the Norwegian Ministry of Defense. According to some sources, NATO has started a decade-long study on how to maintain population security against mini RPAS. But civil society is also interested in the contribution of the Open Society Foundations to the financing of the COUNTER-DRONE SYSTEMS study. More and more studies are emerging regarding the threat posed by the RPAS (for example, in 2008 RAND Corporation published a report on the threat of the RPAS in the USA). Future studies will balance the threat related to the RPAS and the measures to be taken against them. The manufacturing companies are also interested in this sector, the acquisition and development of counterdrone technology being a priority. It is estimated that the C-RPAS market could reach over $\$ 1.5$ billion over the next five years. Which are those events that have recently happened to be related to the RPAS and that made me think?

\section{C-RPAS and major events}

Further, I will present some of the events that have taken place lately related to the use of the RPAS, thus demonstrating the broad spectrum of their use and the need to equip all entities, as soon as possible, in the National Defense System, Public Order and National Security with C-RPAS type devices.

In the USA, "An American who intended to attack the Washington Pentagon and Congress with small models of explosive remote-controlled aircraft was arrested in September 2011 and sentenced to 17 years in prison in Boston, (Massachusetts), announced the US Justice Department" [3]. The 27-year-old Reswan Ferdaus was arrested in 2011 on charges of "attempt to destroy a federal building with the help of explosives" by planes remotely shaped like F-4 Phantom and F-86 Saber aircraft and "attempt to support terrorists", announced the US Department of Justice through the person of prosecutor Carmen Ortiz of Massachusetts. The use of RPAS under various combat-load configurations is no longer a novelty. Can be used by terrorist groups to destroy various targets. And this really happened.

In 2013, a small multi-rotor drone (see 
Figure 1 Angela Merkel at a face-to-face meeting with a mini-drone) was photographed at a rally near German leader Angela Merkel. From here a whole series of comments regarding the vulnerability of the protection and guard services of the dignitaries, due to the use of the RPAS in attacks.

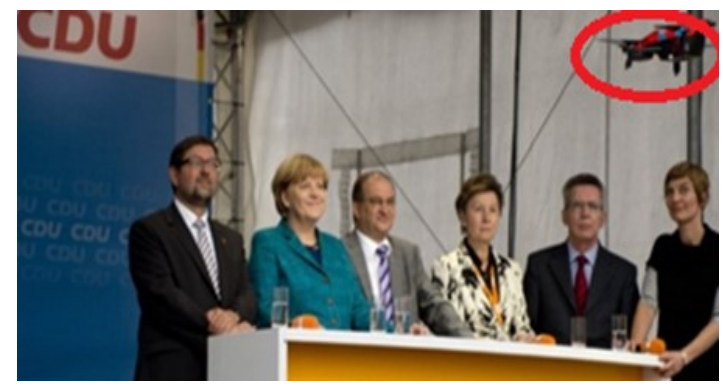

Figure 1: Angela Merkel at a face-to-face meeting with a mini-drone

Source: RT News

French police reported 56 cases of drone use in 2014. Drones were also used in France for illegal surveillance over nuclear power stations between October 5 - October 20, 2014. "Three young people, two men and one woman, were arrested near the Belleville-sur-Loire nuclear power station in the Cher region. Police say the three were preparing to launch a relatively simple drone, the kind that sells on the Internet for 100 euros, writes The Independent"[4]. The allocation of funds for combating the RPAS was measured in accordance, namely 1 million euros to start and develop efficient systems.

In the 2014 conflict in Ukraine, small-size RPAS from First and Second Class were used (see Figure 2 UAV used in Ukraine).

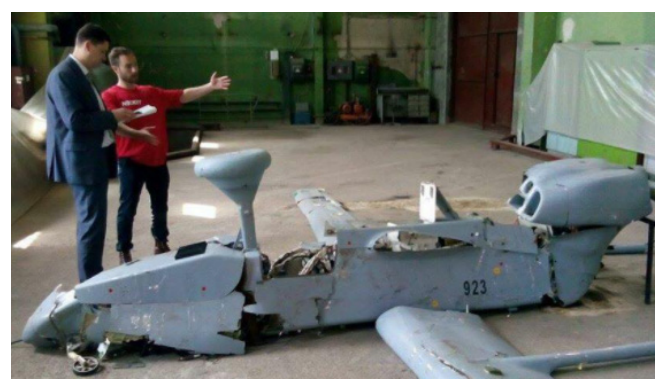

Figure 2: UAV used in Ukraine Source: Bellingcat
PAS are mainly used for border smuggling or in certain prohibited areas. The purpose is, either not to pay the related taxes, or not to show the illegal goods. Such phenomenon is also encountered on the northern border of Romania in the trafficking of cigarettes in Ukraine, but it may occur in any place where the accessibility of the land does not allow for other traffic. The goods are diverse, reaching even drug trafficking (see the case of Tijuana, Mexico, January 20, 2015 on the border between the United States and Mexico). It even came to the delivery of smuggled goods inside certain prisons.

A worrying incident occurred in Japan on April 9, 2015, when radioactive materials were placed on the roof of the Prime Minister of Japan's residence via drones. Combating RPAS is not an easy activity. Even the most sophisticated Patriot defense systems do not face limit situations. Here is an example of a fixed-wing drone (made in Russia), an event that occurred in July 2016, when it survived the attack, both by two Patriot missiles launched by Israeli troops and by air-to-air missiles, launched from an Israeli fighter jet.

At the 2016 Rio de Janeiro Olympics, several drones appeared above the crowds. Under such conditions, even if you place multiple C-RPAS systems, you cannot secure the area, if you do not have enough number systems, to cover the entire restricted airspace. There is also a problem of integrating the different detection sensors, for these C-UAS systems, within the area security system. Problems can also arise when acting with inappropriate interdiction methods, with accident risks for the population in the area.

In the conflict between Syria and Iraq, there are various groups using a large variety of drones. RPAS are also used by organizations such as ISIS, to create terror among theater-fighting forces, with the same effect as guided missiles, but at an extremely low cost, of course maintaining 
the maneuvering proportions. ISIS has claimed to have carried out over 200 such drone attacks in just one year. Actions on Russian military bases in Syria are already known. The Russian army used and uses electronic warfare measures against the RPAS. Improvised drone samples, which attacked their own base from Hemeimim, Al Latakia province, on July 28-29, 2018, were released. The attack occurred with no less than 45 drones. These improvised devices flew up to $100 \mathrm{~km}$. being cataloged in the First Class.

Major General Igor Konashenkov, the spokesman of the Russian Ministry of Defense, says that "the number of drone attacks has increased dramatically recently, and this fashion is likely to produce major effects once it is diversified, and the use will continue and will spread outside the Syrian theater of operations. Thus, the use of drones with explosive or more sophisticated drones, with on-board weapons, can create much greater chaos and attacks, such as political assassinations. Presumably, such a two-drone attack would have been a failed attempt at an attack on Venezuela's President Nicolas Maduro"[5].

A video post is posted on the Internet, which comes to argue the RPAS producers' intention is to use them as highly effective weapons for killing and why not for murder. The mini- drone can perform the facial recognition of the victim by scanning and can be programmed to kill (automatically or on request) in confined spaces, after confirming its identity.

What is worth to remember is the fact that although the attack on the Russian base was unsuccessful, no one can guarantee that it will be that way all the time, raising concern for the commanders in charge. We must acknowledge that the RPAS represents real challenges for maintaining the security of the armies that currently have troops in the theater of operations. An official of the US Army, talking about the conflict between Syria and Iraq, actually told the truth about airspace control under 3,500 meters, namely that it actually does not exist. It is sad but true. This means that pilots of all aircraft face a big problem below this height. In fact, concern is raised about a potential collision between a crewed aircraft and the RPAS. The consequences could be catastrophic, if the collision were in the sensitive areas of the crew aircraft (intake ports, control area, etc.).

Moreover, the US Department of Defense has intensified its research and development of C-RPAS systems, especially in their role in terms of protecting the force deployed in the theater of operations, but also on the protection of critical infrastructures in the country. Under the appearance of events considered "mistakes" or "random accidents", hostile military interests may be hidden, verifying the reaction of the authorities to such events. And here we can mention the accidental collapse of a DJI type RPAS, on the White House ground in 2015, as well as the numerous reports of dangerous flight, in the proximity of the aircraft with human crew on board, or near airports.

On December 19-20, 2018, at the second largest airport in London, Gatwick, flights were suspended due to drones [6]. The activity was halted for several hours due to the repeated appearance of drones in the airport security area. In this situation the damage is immense due to the redirection of the aircraft in flight to other airports or the maintenance of aircraft on the ground. The airports that supported this conflict were Luton, Heathrow and Stansted as well as those in Paris and Amsterdam. In order to form an image regarding the implications due to the drone incident, the source who mentioned the news, evaluated a total of 111,000 passengers affected, out of a total of 760 flights [7]. I will not mention the serious situation of the impact of drones with aircraft full of passengers and the very high probability of a catastrophe. 
In the United Kingdom two years ago, there were 92 collision incidents, avoided at the border between private drones and airplanes, tripling their number between 2015-2017 (according to the mechanism that monitors the events in question, the UK Airprox Board [8]). The Metropolitan Police was notified based on reports that drones were observed near Heathrow Airport at around 5 P.M. The incident happened three days after the events at Gatwick Airport (fully reopened on December 21, 2018) [9].

Authorities have begun investigating these incidents, including arrests and prosecutions for using unauthorized drones near airports. Thus, "a man of Romanian origin was accused of using a drone near Heathrow Airport on December 24" [10]. Also, London's Police arrested 5 people, environmental activists, for implication in planning a drone protest at Heathrow airport [11].

\section{Conclusions}

The unauthorized flights of the RPAS represent serious threats to the security of the aircraft with human crew on board, to the security of the troops in the theater of operations, as well as to the critical infrastructures and why not to the security of the civilian population.

Due to the intensification of the activity with the RPAS and European regulations such as COMMISSION REGULATION (EU) 2019/947 of 24 May 2019 on the rules and procedures for operating unmanned aircraft and Commission Delegated Regulation (EU) 2019/945 of March 12,
2019 on unmanned aircraft systems and third-country unmanned aircraft system operators, which will allow the drones to operate in the European airspace, the highest priority is to take measures to combat unauthorized flights. Among these measures, C-RPAS systems can successfully cope with these challenges, if and only if they keep up with the evolution of RPAS and if they are used with maximum efficiency, depending on the sensors on board and depending on their combative capabilities. Firms in the RPAS construction industry can help ensure airspace security by introducing flight restriction programs in restricted areas within the drone software. Moreover, they can collaborate effectively with companies in the C-RPAS construction industry. Of course, these aspects are especially applicable for civil RPAS.

So, whether we want to acknowledge it or not, whether the Romanian Army will be able to purchase C-RPAS systems in the near future or not, the Romanian society as a whole will have to participate in the development effort, both in the RPAS sector and in the C-RPAS sector, at least for economic, security and (military) reasons. Where exactly will we end up with RPAS and C-RPAS? To what extent will they work independently? How much more do we have to learn? When will this field reach maturity? There are many more questions generated by the knowledge of this field. As P.S. Laplace said, "the wider the area explored, the wider the borders of the unknown".

\section{References List}

[1] A. H. Michel. COUNTER-DRONE SYSTEMS, 2nd Edition, Center for the Study of the Drone at Bard College, December 2019, p.18-42

[2] Global Counter UAS Market, Forecast to 2024 [Internet]. Frost \& Sullivan; [09/10/2019; 18/10/2020]. Available from: https://store.frost.com/global-counter-uasmarket-forecast-to-2024.html 
[3] I. Gaidau. THE AMERICAN WHO WANTED TO BLOW UP THE PENTAGON AND THE CONGRESS WITH REMOTE-CONTROLLED PLANES WAS SENTENCED TO 17 YEARS IN PRISON [Internet]. Mediafax; [02/11/2012; 18/10/2020]. Available from: https://www.mediafax.ro/externe/americanul-care-voiasa-arunce-in-aer-pentagonul-si-congresul-cu-avioane-teleghidate-a-fost-condamnat-la17-ani-de-inchisoare-10272936

[4] A. Varzaru. ARRESTS IN THE DRONE SCANDAL OVER NUCLEAR POWER PLANTS IN FRANCE [Internet]. Ziare.com; [10/11/2014; 19/10/2020]. Available from: https://ziare.com/europa/franta/arestari-in-scandalul-dronelor-de-deasupracentralelor-nucleare-din-franta-1332427

[5] I.Chifu. ARTISANAL DRONE ATTACKS ON RUSSIAN BASES, THE LATEST FAD IN SYRIA [Internet]. Adevarul.ro; [21/08/2018; 19/10/2020]. Available from: https://adevarul.ro/international/in-lume/atacuri-drone-artizanale-bazelor-ruse-ultimamoda-siria-1_5b7bc281df52022f759e984b/index.html

[6] P. Dobrescu. LONDON GATWICK AIRPORT HAS SUSPENDED FLIGHTS DUE TO DRONES [Internet]. Libertatea; [20/12/2018; 19/10/2020]. Available from: https://www.libertatea.ro/stiri/aeroportul-gatwick-suspendat-zborurile-din-cauza-unordrone-2493138

[7] G. Stanciu. AIRPORT CLOSED DUE TO IDIOTS WITH DRONES [Internet]. PLAYTECH; [20/12/2018; 19/10/2020]. Available from: https://playtech.ro/2018/aeroport-inchis-zbor-drone-gatwick/

[8] P. Dobrescu. LONDON GATWICK AIRPORT HAS SUSPENDED FLIGHTS DUE TO DRONES [Internet]. Libertatea; [20/12/2018; 19/10/2020]. Available from: https://www.libertatea.ro/stiri/aeroportul-gatwick-suspendat-zborurile-din-cauza-unordrone-2493138

[9] MAN CHARGED OVER HEATHROW DRONE INCIDENT DAYS AFTER GATWICK CHAOS [Internet]. The Telegraph; [20/01/2019; 19/10/2020]. Available from: https://www.telegraph.co.uk/news/2019/01/20/man-charged-heathrow-droneincident-days-gatwick-chaos/

[10] ROMANIAN ACCUSED IN THE DRONE SCANDAL AT HEATHROW AIRPORT [Internet]. Digi24; [20/01/2019; 19/10/2020]. Available from: https://www.digi24.ro/stiri/externe/ue/roman-acuzat-in-scandalul-dronelor-de-peaeroportul-heathrow-1067953

[11] LONDON POLICE ARREST 5 FOR ROLE IN PLANNING FRIDAY DRONE PROTEST AT HEATHROW AIRPORT [Internet]. USA TODAY TRAVEL; [n.a.; 19/10/2020]. Available from:

https://eu.usatoday.com/story/travel/news/2019/09/13/heathrow-airport-5-arrested-roleplanned-friday-drone-protest/2309215001/ 